\title{
Effect of Various Polymeric Crystal Modifiers and Solvents Formulations on the Prevention of Wax and Asphaltene Formation in Crude Oil Pipelines
}

\author{
Anisuzzaman S M1,2*, Krishnaiah $\mathbf{D}^{2}$ and Madsah $\mathbf{M}^{2}$ \\ ${ }^{1}$ Energy Research Unit (ERU), Malaysia \\ ${ }^{2}$ Chemical Engineering Programme, Faculty of Engineering, Universiti Malaysia \\ Sabah, 88400 Kota Kinabalu, Sabah, Malaysia
}

*Corresponding author: Anisuzzaman S M, Chemical Engineering Programme, Faculty of Engineering, Universiti Malaysia Sabah, 88400 Kota Kinabalu, Sabah, Malaysia, Tel: +6088 320000; Email: anis_zaman@ums.edu.my / dr.anis.ums@gmail.com

\section{Abstract}

Transportation of crude oil from offshore platform to onshore has been recognized as one of the challenges faced by oil and gas industry as the pipelines are deposited by wax and asphaltene. This research investigated the efficiency of three types of crystal modifiers, namely ethyl-vinyl acetate (EVA25 and EVA40), and styrene maleic anhydride (SMA); and two types of solvents, methylcyclohexane (MCH) and para-xylene, in different ratios to formulate the best inhibitor. The best formulation for EVA-based inhibitor was $30 \mathrm{wt} \%$ crystal modifiers and $70 \mathrm{wt} \%$ para-xylene, while the best formulation for SMA was $30 \mathrm{wt} \%$ SMA and $70 \mathrm{wt} \% \mathrm{MCH}$ which could give viscosity reduction as high as $86.37 \%$. All three types of crystal modifiers showed almost the same efficiency. Para-xylene was found to be the best solvent as it acted as solvent for the crystal modifiers and also as the asphaltene dispersant. The efficiency of the inhibitor decreased when the solvent used was a combination of two types of compounds. An optimization study showed that the most optimum conditions were found to be $42.02 \%, 3.34 \%$ and $54.65 \%$ for EVA25, MCH and para-xylene respectively.

Keywords: Ethylene-vinyl acetate (EVA); Response surface methodology (RSM); Optimizationp; Viscosity; Wax inhibitor

\section{Introduction}

It is greatly known that crude oil is a mixture of hydrocarbons containing aromatic components, paraffins, asphaltenes and resins. The production and the transport of crude oil along the pipelines is one of the greatest challenges encountered by oil and gas industry especially in the offshore [1]. This is due to the existence of paraffin wax in the crude oil that becomes solid at low temperature which will deposit on the wall of the pipelines and will reduce the flow ability of the crude oil. This situation will lead to the reduction of diameter of the 


\section{Petroleum \& Petrochemical Engineering Journal}

pipelines, pressure drop and will reduce the amount of crude oil transported, eventually leads to costly maintenance and remediation methods [2,3].

The crude oil contains asphaltene which stabilized micelles due to high pressure and the action of resins and maltenes which acts as precursors to stabilize asphaltene micelles. If the amount of resins in the crude oil is reduced or too limited, then micelles can be formed by multiple asphaltene molecules [4]. Besides that, due to pressure drop, lighter hydrocarbons and gases which acts as a solvent for asphaltene can become gaseous, leaving the remaining liquid crude oil to be less polar, causing the flocculation of asphaltene. Asphaltene, unlike waxes, will aggregate and flocculate rather than formation of solid or solid-like structure. There are three stages to the flocculation process. First, the compounds crystallize at a crude oil temperature below the wax appearance temperature (WAT) forming crystal nucleus. At the second stage, more molecules precipitate and grow upon the nucleus. At the third stage, the grown crystals deposit on the surface walls of pipelines and production facilities [5].

Deposition of wax on the wall of the pipeline occurs when there is a temperature difference between the colder pipelines surface and the crude oil at the centre of the pipelines [6-8]. Several methods and techniques have been developed to tackle the wax crystallization problem caused by the paraffin wax deposition. Among the techniques that has been developed are based on mechanical, thermal or chemical means [2]. Researchers are now interested with the chemical methods as the alternative to inhibit the wax deposition. The reason behind it is because of the current pigging method costly to perform while using additive. The wax chemical inhibitor is cheaper compared to the pigging method [9].

The asphaltene is the most aromatic and polar fraction molecule. The oil constitutes asphaltene which is high molecular weight, associate or aggregate in solutions, and has limited solubility in crude oil [10]. However, the deposition of the organic solid is one of the critical problems faced in transportation of the crude oil. In contrast to wax, it is a very common problem for asphaltene to deposit near the flocculation onset pressure. When there is declining of pressure inside the reservoir due to its exploitation, the system might undergo asphaltenes deposition [11]. The solubility parameter for asphaltene and the crude oil can greatly affect the amount of asphaltene that is soluble in the crude oil. If the solubility parameter for asphaltene is the same or higher than crude oil, therefore more asphlatene will be soluble in the oil. Because the solubility parameter is presented in the function of temperature, thus increasing the temperatures will cause a decrease in asphaltene solubility parameter to decrease the amount of asphaltene that will be soluble in crude oil.

Nonetheless, the existence of asphaltene also will affect the behaviour of paraffin wax. The asphaltenes that flocculate together might provide the site for wax crystallization and also clogging of production facilities [12-16]. A recent study presented that waxes and asphaltenes build a complex agglomerates that act the same as the sediments that are found on bottom of storage tanks [17]. Therefore, there is a need to prevent the asphaltene from flocculating together. Two general methods exist for asphaltene remediation which is mechanical method and using chemical solvents to dissolve deposited asphaltene [2]. Although asphaltenes are insoluble in alkanes, they are greatly soluble in aromatic solvents like benzene [18].

This research aim is to study and comparatively evaluate the effect of chemical inhibitor comprising of wax crystal modifiers and aromatic solvents to inhibit wax and asphaltene deposition in crude oil. For this reason, the viscosity of crude oil is tested with different polymers and solvents; then the performance for each combination was evaluated to find the best combination for chemical inhibitor. The crystal modifiers used in this study were ethyl-vinyl acetate (EVA25 and EVA40) and poly(styrene-co-maleic) anhydride (SMA), and the solvents were methylcyclohexane (MCH) and para-xylene. Moreover, response surface methodology (RSM) was used to optimize the ratio of each chemical that is formulated together to form inhibitors $[19,20]$.

\section{Methodology}

\section{Preparation of Inhibitor}

The crystal modifiers (EVA25, EVA40 and SMA) and the solvents (MCH and para-xylene) were obtained from Sigma Aldrich. The inhibitor is prepared by mixing the crystal modifier with the solvent in different ratios. The total of the inhibitor should be $2 \mathrm{wt} \%$ from the total weight of the crude oil. The solvents were weighed separately and heated in a water bath at $60^{\circ} \mathrm{C}$ before mixing with the crystal modifier. After mixing, the temperature of the water bath was increased to $85^{\circ} \mathrm{C}$ to melt the crystal modifier completely. 


\section{Petroleum \& Petrochemical Engineering Journal}

\section{Preparation of Crude Oil}

The crude oil to be tested in this study was Malaysian crude oil, specifically taken from Sabah platform, Malaysia. Malaysian crude oil generally has very little amount of wax but high content of asphaltene [12,21,22]. Before mixing the inhibitor with the crude oil, the crude oil was heated overnight at $90^{\circ} \mathrm{C}$ to melt the wax inside it. The crude oil was poured into the inhibitor and stored at $90^{\circ} \mathrm{C}$ for $30 \mathrm{~min}$ to let the inhibitor to react with the wax.

\section{Viscosity Test}

The samples were then cooled to $5^{\circ} \mathrm{C}$ in ice bath to imitate the subsea environment. The viscosity of the samples was tested using Brookfield Programmable Viscometer DV-II + Rheometer. The data points are avarege of three experimental results. The equipments setup is shown in Figure 1.

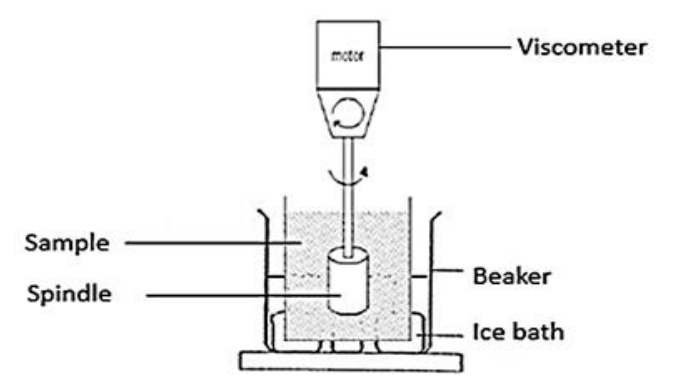

Figure 1: The schematic setup of the equipment.

\section{Design of Experiments using RSM}

In this work, D-optimal of RSM (Design Expert 7.0 program) was used to optimize the ratio of each chemical that can be formulated together to form inhibitors.

\section{Results and Discussion}

\section{Performance of the Inhibitor in Different Ratio of Crystal Modifiers and Solvents}

The results for the different combination of inhibitor are shown in Table 1 for EVA25, EVA40 and SMA with different ratios of solvents. The result indicated that the ratio of polymer and the solvents had a major effect towards the inhibitor.

Figure 2 shows the performance of EVA25 based inhibitor towards the viscosity of the crude oil.

\begin{tabular}{|c|c|c|c|c|}
\hline Type of Polymer & $\begin{array}{c}\text { Polymer Weight } \\
\text { Percentage (wt\%) }\end{array}$ & $\begin{array}{c}\text { Solvent Ratio (MCH:p- } \\
\text { xylene) (wt\%) }\end{array}$ & Viscosity (cP), $5^{\circ} \mathrm{C}$ & $\begin{array}{c}\text { Viscosity Reduction } \\
\text { Percentage (\%) }\end{array}$ \\
\hline \multicolumn{3}{|c|}{ Blank } & 164.4 & - \\
\hline \multirow{13}{*}{ EVA25 } & \multirow{5}{*}{30} & $0: 70$ & 22.70 & 86.2 \\
\hline & & $20: 50$ & 24.40 & 85.2 \\
\hline & & $35: 35$ & 44.80 & 72.7 \\
\hline & & $50: 20$ & 74.40 & 54.7 \\
\hline & & $70: 0$ & 39.60 & 75.9 \\
\hline & \multirow{5}{*}{50} & $0: 50$ & 22.80 & 86.1 \\
\hline & & $10: 40$ & 25.60 & 84.4 \\
\hline & & $25: 25$ & 31.10 & 81.1 \\
\hline & & $40: 10$ & 42.00 & 74.5 \\
\hline & & $50: 0$ & 27.60 & 83.2 \\
\hline & \multirow{3}{*}{70} & $0: 30$ & 28.80 & 82.5 \\
\hline & & $10: 20$ & 33.60 & 79.6 \\
\hline & & $15: 15$ & 56.40 & 65.7 \\
\hline
\end{tabular}




\section{Petroleum \& Petrochemical Engineering Journal}

\begin{tabular}{|c|c|c|c|c|}
\hline & & $20: 10$ & 52.80 & 67.9 \\
\hline & & $30: 0$ & 43.20 & 73.7 \\
\hline \multirow{15}{*}{ EVA40 } & \multirow{5}{*}{30} & $0: 70$ & 31.20 & 86.9 \\
\hline & & $20: 50$ & 48.00 & 70.8 \\
\hline & & $35: 35$ & 69.60 & 57.7 \\
\hline & & $50: 20$ & 61.20 & 62.8 \\
\hline & & 70:0 & 24.00 & 85.4 \\
\hline & \multirow{5}{*}{50} & $0: 50$ & 26.40 & 83.9 \\
\hline & & $10: 40$ & 45.60 & 72.3 \\
\hline & & $25: 25$ & 32.40 & 80.3 \\
\hline & & $40: 10$ & 75.60 & 54.0 \\
\hline & & $50: 0$ & 37.20 & 83.2 \\
\hline & \multirow{5}{*}{70} & $0: 30$ & 21.60 & 77.4 \\
\hline & & $10: 20$ & 68.40 & 70.8 \\
\hline & & $15: 15$ & 52.80 & 57.7 \\
\hline & & $20: 10$ & 74.40 & 62.8 \\
\hline & & $30: 0$ & 27.60 & 81.0 \\
\hline \multirow{15}{*}{ SMA } & \multirow{5}{*}{30} & $0: 70$ & 31.60 & 80.8 \\
\hline & & $20: 50$ & 37.20 & 77.4 \\
\hline & & $35: 35$ & 88.80 & 46.0 \\
\hline & & $50: 20$ & 45.80 & 72.1 \\
\hline & & $70: 0$ & 22.80 & 86.1 \\
\hline & \multirow{5}{*}{50} & $0: 50$ & 45.60 & 72.3 \\
\hline & & $10: 40$ & 44.40 & 73.0 \\
\hline & & $25: 25$ & 72.00 & 56.2 \\
\hline & & $40: 10$ & 63.60 & 61.3 \\
\hline & & $50: 0$ & 37.20 & 77.4 \\
\hline & \multirow{5}{*}{70} & $0: 30$ & 44.40 & 73.0 \\
\hline & & $10: 20$ & 45.60 & 72.3 \\
\hline & & $15: 15$ & 85.20 & 48.2 \\
\hline & & $20: 10$ & 69.60 & 57.7 \\
\hline & & $30: 0$ & 38.40 & 76.6 \\
\hline
\end{tabular}

Table 1: Viscosity of the oil treated with wax inhibitor.

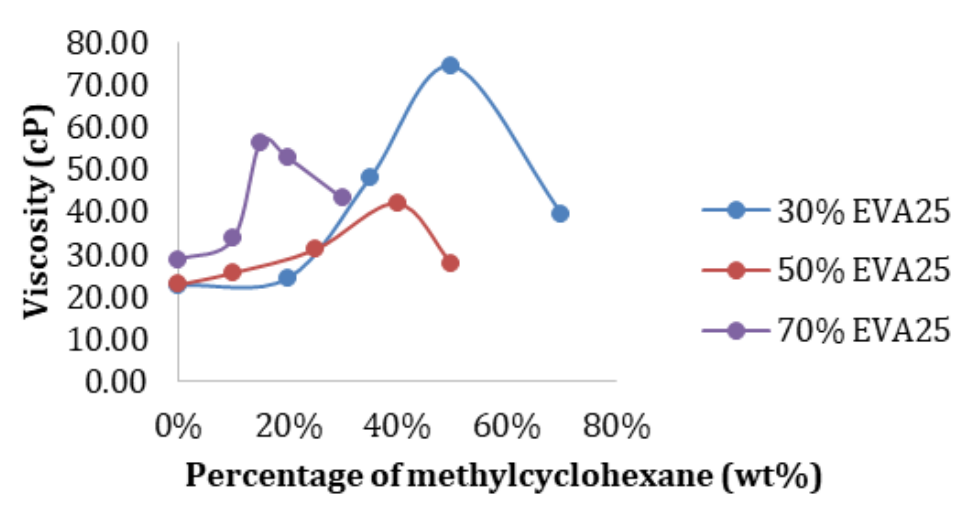

Figure 2: Performance of EVA 25 towards the viscosity of crude oil. 


\section{Petroleum \& Petrochemical Engineering Journal}

Figure 2 shows that the viscosity of the crude oil was the lowest when the inhibitor used was $30 \mathrm{wt} \%$ and 50 wt $\%$ of EVA2 5 as the crystal modifiers. As the wt\% of $\mathrm{MCH}$ increased, the performance of the inhibitor decreased until a point and increased again. For $30 \mathrm{wt} \%$ of EVA25, the performance decreased until the wt\% of $\mathrm{MCH}$ increased to $50 \mathrm{wt} \%$. However, the inhibitor decreased the viscosity of crude oil back when $70 \%$ of $\mathrm{MCH}$ used. Nonetheless, the viscosity did not exhibit as low as when using $30 \mathrm{wt} \% \mathrm{MCH}$ and $70 \mathrm{wt} \%$ para-xylene. The lowest viscosity reached was $22.70 \mathrm{cP}$ when using 30 wt $\%$ EVA25, 0 wt $\%$ MCH, 70 wt $\%$ para-xylene. The viscosity was slightly higher which is $22.80 \mathrm{cP}$, when using 50 wt\% EVA25, 0 wt\% MCH, 50 wt $\%$ para-xylene. The same trend has been observed for EVA40 and SMA.

Figure 3 shows the result of EVA40 as the crystal modifiers towards the viscosity of the crude oil. Exhibiting the same trend as EVA25, $30 \mathrm{wt} \%$ EVA40, $0 \mathrm{wt} \% \mathrm{MCH}, 70$ wt $\%$ para-xylene gave the most reduction in viscosity of the crude oil as low as $21.60 \mathrm{cP}$ compared to $50 \mathrm{wt} \%$ and $70 \mathrm{wt} \%$ of EVA40 which were slightly higher.

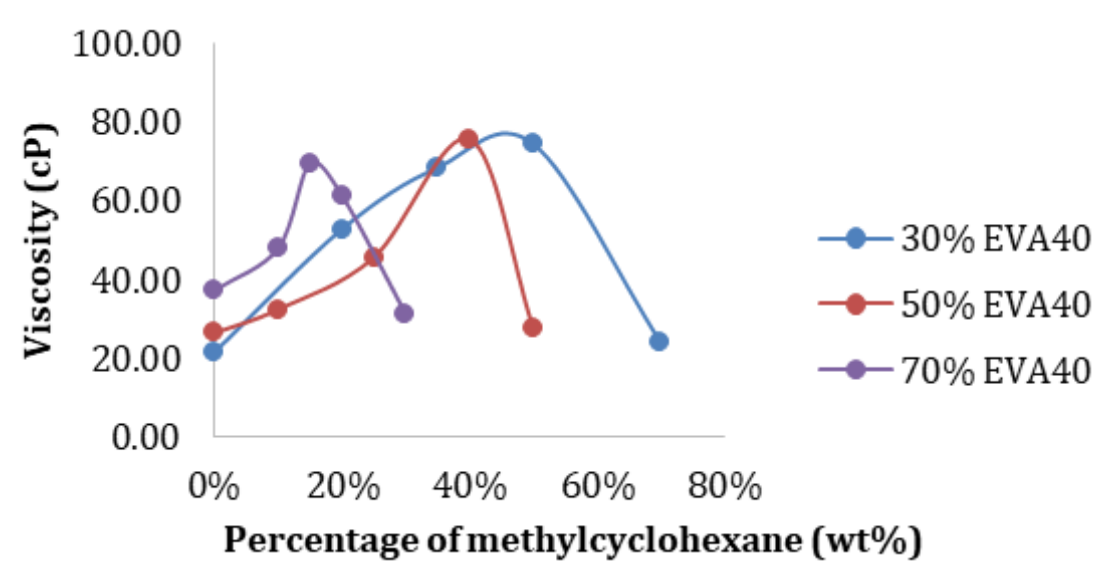

Figure 3: Performance of EVA 40 towards the viscosity of crude oil.

The reason for this might be caused by the molecular weight of the vinyl acetate $(40 \% \mathrm{w} / \mathrm{w})$. It has been widely known that different quantity of the vinyl acetate will exhibit different capacity to control the size of the crystal wax formed [23]. It was found that the lower EVA alter the formation of wax crystal effectively at higher concentrations than higher EVA [24]. It was reported that higher EVA grade encourage more wax crystals to form at low concentrations. Nevertheless, the result for EVA25 deviated from this finding might be caused by the lack of solvent to dissolve the solid EVA25 as the weight percentage of the solid crystal modifiers increased. The result showed that lower concentration of EVA25 gave better result when compared with higher concentration and this result is similar to our earlier studies findings [21,22].

Figure 4, shows the results when SMA was used as the crystal modifier. The lowest crude oil viscosity is $21.60 \mathrm{cP}$ where the combination of SMA, MCH and para-xylene were $30 \mathrm{wt} \%, 70 \mathrm{wt} \%, 0 \mathrm{wt} \%$ respectively. When using 30 wt $\%$ SMA, 0 wt $\%$ MCH, 70 wt $\%$ para-xylene, the viscosity was slightly higher which was $31.60 \mathrm{cP}$. Nevertheless, although 30 wt $\%$ of SMA gave the best viscosity reduction compared to $50 \mathrm{wt} \%$ and $70 \mathrm{wt} \%$ of SMA, when the combination of the inhibitor was $30 \mathrm{wt} \%$, $35 \mathrm{wt} \%, 35 \mathrm{wt} \%$ respectively for SMA, MCH and paraxylene gave the lowest viscosity reduction. The viscosity of the crude oil only decreased as low as $88.80 \mathrm{cP}$. Table 1 shows the highest percentage reduction for every crystal modifiers with different formulations. The performance for every type of crystal modifiers gave almost the same viscosity percentage reduction with different formulation. It can be seen that the highest percentage reduction of these three types of inhibitor reached up to $86 \%$.

Lashkarbolooki [25] discovered that 50 wt\% EVA, 25 wt $\%$ acetone and $25 \mathrm{wt} \%$ p-xylene gave viscosity reduction up to $53 \%$. However, in our earlier studies we have reported that the best formulation for EVA-based 


\section{Petroleum \& Petrochemical Engineering Journal}

inhibitor was 50 wt $\%$ EVA, 25 wt $\% \mathrm{MCH}$ and $25 \mathrm{wt} \%$ toluene, which gave reduction of $67 \%$ when $1 \%$ of inhibitor applied [21]. Soni [26,27] developed inhibitors based on maleic anhydride and the reduction was up to
$67 \%$. Moreover, it has proved that the percentage reduction can go further up to $86 \%$ for Malaysia crude oil $[21,22,28]$.

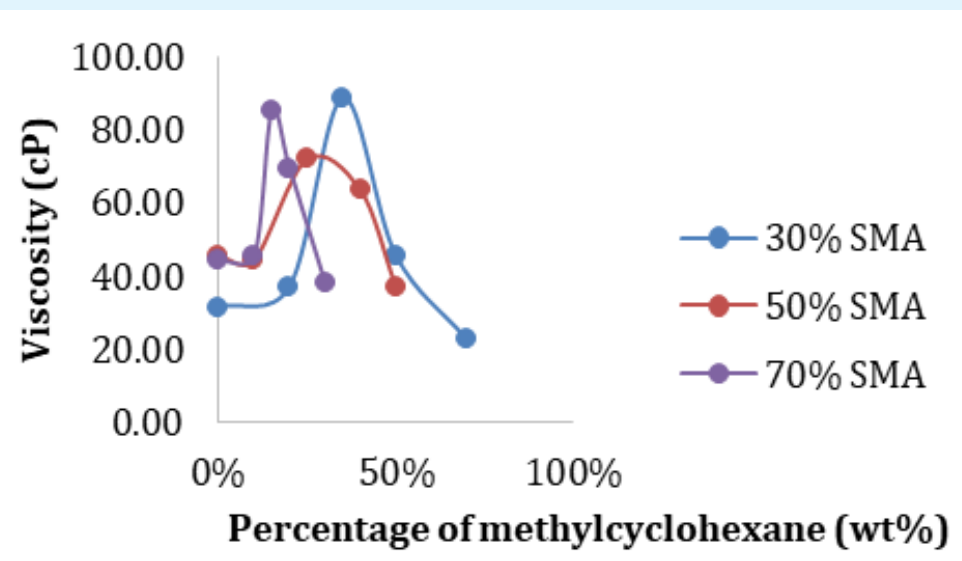

Figure 4: Performance of SMA towards the viscosity of crude oil.

\section{Performance of the Inhibitor in Terms of Solvent}

Figure 5 shows the percentage reduction of crude oil viscosity using different solvents.

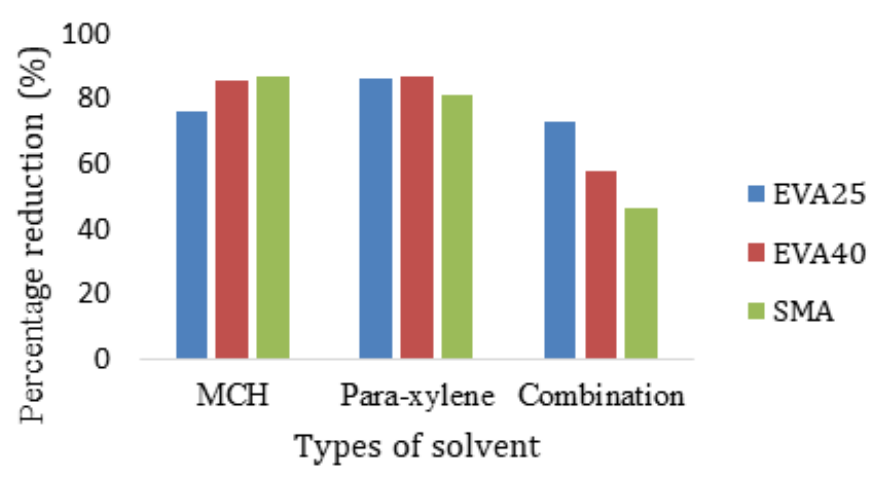

Figure 5: Percentage reduction of crude oil viscosity using different solvents.

From the Figure 5, it can be seen that the three crystal modifiers decreased in efficiency when the solvent was a combination of two components when $70 \mathrm{wt} \%$ of solvent used. The efficiency improved when the solvent was purely MCH or para-xylene only. This condition may be due to the polarity and the chemical properties of the crystal modifiers and the solvents, the ability of the solvent to dissolve the solid and the ability of the solvent to act as asphaltene dispersant. 


\section{Petroleum \& Petrochemical Engineering Journal}

García [14] investigated the efficiency of maleic anhydride-based inhibitor in $\mathrm{C}_{24+}$ waxes and found that the presence of asphaltenes in crude oil would interfere with crystal inhibition as asphaltene will generate crystallization site. This phenomenon was then supported by Machado and Lucas [29]. They discovered that the existence of petroleum asphalt will reduce the efficiency of EVA based inhibitor. Nonetheless, the presence of aromatic compound such as para-xylene in the formulation aided to disperse the asphaltenes molecules in the crude oil because the solubility of asphaltenes increase proportionally with the increase of para-xylene $[30,31]$. Thus higher ratio of para-xylene in the formulation gaves better result on viscosity reduction.

It was widely known that the best solvent for inhibition of viscosity is aromatic compound [9]. Thus, EVA25 and EVA40 can dissolve completely in adequate quality of MCH and para-xylene. When compared with the other two crystal modifiers, SMA can dissolve better in ether and ketone-based solvent. Due to this fact, SMA which is in solid form, cannot dissolve completely to inhibit the wax formation.

\section{Development of Regression Model Equations using Mixture Design in D-optimal}

For the evaluation of the regression model, EVA25 has been selected as it gave the best reduction between the three polymers. Reduced cubic regression analysis using
ANOVA was chosen to estimate the significance of each coefficient, which is also exhibited the level of interaction between each independent parameter. The model in terms of actual responses of viscosity of the crude oil was regressed by mainly considering the significant terms and expressed by equation 1 :

Viscosity $(c P)=$ $32.02 A+41.59 B+21.73 C+15.44 A B+65.80 B C+$ 207.90AB $(A-B)$ Equation (1)

where $\mathrm{A}, \mathrm{B}$ and $\mathrm{C}$ represent weight percentage of EVA, $\mathrm{MCH}$ and para-xylene, respectively.

\section{Statistical Analysis}

Table 2 shows the analysis of variance (ANOVA) for the experiment. The model was extremely significant $(p=0.001)$ and the coefficient determination, $R^{2}$ was calculated as 0.8888 which indicated $88.88 \%$ of the variability in the response can be explained by the model and less than $12 \%$ of the total variations could not be explained by the model. The adjusted determination coefficient value (Adj. $R^{2}=0.8054$ ) was within reasonable agreement with the predicted $R^{2}$ of 0.8888 and it also strongly indicated the significance of the model. For reduced cubic model, the insignificant terms, mainly parameter $\mathrm{C}$ have been omitted to improve the model.

\begin{tabular}{|c|c|c|c|c|c|c|}
\hline Source & Sum of squares & DF & Mean square & F Value & $\begin{array}{c}\text { p-value } \\
\text { Prob }>\text { F }\end{array}$ & \\
\hline Model & 2700.24 & 6 & 450.04 & 10.66 & 0.0019 & Significant \\
\hline Linear mixture & 807.60 & 2 & 403.80 & 9.56 & 0.0076 & \\
\hline $\mathrm{AB}$ & 8.93 & 1 & 8.93 & 0.21 & 0.6579 & \\
\hline $\mathrm{BC}$ & 305.24 & 1 & 305.24 & 7.23 & 0.0275 & \\
\hline$A B(A-B)$ & 452.93 & 1 & 452.93 & 10.73 & 0.0113 & \\
\hline $\mathrm{BC}(\mathrm{B}-\mathrm{C})$ & 859.69 & 1 & 859.69 & 20.36 & 0.0020 & \\
\hline Residual & 337.78 & 8 & 42.22 & & & \\
\hline Cor Total & 3038.02 & 14 & & & & \\
\hline \multicolumn{2}{|c|}{ Standard deviation $=6.50$} & & $a n=37.99$ & \multirow{2}{*}{\multicolumn{3}{|c|}{ Adequate precision $=11.416$}} \\
\hline \multicolumn{2}{|c|}{$R^{2}=0.8888$} & & $R^{2}=0.8054$ & & & \\
\hline
\end{tabular}

Table 2: Analysis of variance (ANOVA) for the experimental results of the D-optimal cubic model for viscosity.

\section{Effects of Individual Variables and their Interactions}

Figure 6 shows the three-dimensional (3D) plots of the combined effect of the three parameters for the viscosity of the crude oil. 


\section{Petroleum \& Petrochemical Engineering Journal}

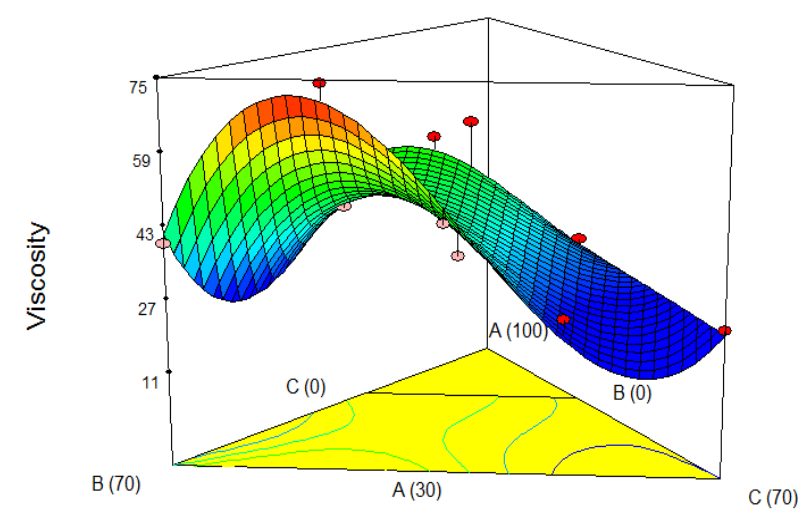

Figure 6: Response surface curve (3D plots) of viscosity (cP) of crude oil for the combination of EVA (wt\%), MCH (wt\%) and p-xylene (wt\%) as the wax and asphaltene inhibitor.

As shown in Figure 6, the effect of varying the weight percentage of EVA25 (A), weight percentage of MCH (B) and weight percentage of para-xylene $(C)$ respectively on the viscosity of the crude oil. Although single parameter $\mathrm{C}$ has been removed, the interaction of cubic terms BC(B-C) has the greatest effect on the response. While the interaction of $\mathrm{AB}$ has the least significant effect towards the viscosity.

\section{Process 0ptimization}

The optimization of combinations of EVA, MCH and para-xylene to improve viscosity of crude oil was carried out by using Design-Expert software 7.0 (Stat-Ease, Inc.,
Minneapolis, MN 55413, USA). The optimum conditions for the three variables are shown in Table 3. Under these optimum conditions, the viscosity obtained was $22.4 \mathrm{cP}$. The deviation of the result obtained from the predicted optimized combination is about $7.8 \%$ percent. Nonetheless, this optimized conditions can reduce the viscosity up to $86.37 \%$.

From the verification of the optimized conditions, it was found that under optimized conditions the viscosity could reduce further up to $86.37 \%$. Thus, the result agrees with the agreement that polymeric inhibitor is effective to reduce the viscosity of Malaysia crude oil.

\begin{tabular}{|c|c|c|}
\hline Variables & Target/Goal & Optimized Condition \\
\hline EVA (wt\%) & In range & 42.02 \\
\hline MCH (wt\%) & In range & 3.34 \\
\hline Para-xylene (wt\%) & In range & 54.65 \\
\hline Responses & Minimize & 20.66 \\
\hline Viscosity of crude oil (cP) & \multicolumn{2}{|c|}{1.00} \\
\hline Desirability & \multicolumn{2}{|c|}{} \\
\hline
\end{tabular}

Table 3: Optimized condition for every parameter.

\section{Conclusion}

It can be observed that all three types of crystal modifiers gave almost the same efficiency to inhibit wax and asphaltenes formation, which reduced the crude oil viscosity up to $86 \%$. The best formulation for EVA-based inhibitor was $30 \mathrm{wt} \%$ crystal modifiers, $70 \mathrm{wt} \%$ para- xylene, while the best formulation for SMA was $30 \mathrm{wt} \%$ SMA, $70 \mathrm{wt} \% \mathrm{MCH}$. Using only one type of solvent was found better than the combination of two solvents. Nonetheless, para-xylene has a better efficiency to reduce viscosity due to the fact that it was suitable as asphaltene dispersant. The optimization of the process has reduced the viscosity up to $86.37 \%$. 


\section{Petroleum \& Petrochemical Engineering Journal}

\section{Acknowledgement}

The authors would like to express greatest appreciation to the Centre of Research and Innovation (PPI), Universiti Malaysia Sabah (UMS) for the support to this study (Grant No. SBK0346-2017).

\section{References}

1. Machado AL, Lucas EF, González G (2001) Poly(ethylene-co-vinyl acetate) (EVA) as wax inhibitor of a Brazilian crude oil: oil viscosity, pour point and phase behavior of organic solutions. J Petrol Sci Eng 32(2-4): 159-165.

2. Guo B, Song S, Ghalambor A, Lin TR, Guo B, Song S, Li, TR (2014) Offshore pipelines, Design, Installation, and Maintenance. $2^{\text {nd }}$ (Edn.), Gulf Professional Publishing, pp: 179-231.

3. Bello O, Fasesan S, Teodoriu C, Reinicke K (2006) An evaluation of the performance of selected wax inhibitors on paraffin deposition of nigerian crude oils. Pet Sci Technol 24(2): 195-206.

4. Andersen SI, Speight JG (2001) Petroleum resins: separation, character, and role in petroleum. Pet Sci Technol 19(1-2): 1-34.

5. Tharanivasan A (2012) Asphaltene precipitation from crude oil blends, conventional oils and oils with emulsified water. Ph.D Thesis, University of Calgary, Alberta.

6. Aiyejina A, Chakrabarti DP, Pilgrim A Sastry MKS (2011) Wax formation in oil pipelines: A critical review. Int J Multiphas Flow 37(7): 671-694.

7. Jennings DW, Weispfennig K (2005) Effects of shear and temperature on wax deposition: coldfinger investigation with a gulf of Mexico crude oil. Energ Fuel 19(4): 1376-1386.

8. Jennings DW, Breitigam J (2010) Paraffin inhibitor formulations for different application environments: From heated injection in the desert to extreme cold arctic temperatures. Energ Fuel 24(4): 2337-2349.

9. Wei B (2015) Recent advances on mitigating wax problem using polymeric wax crystal modifier. J Pet Explor Prod Technol 5(4): 391-401.
10. Ganeeva YM, Yusupova TN, Romanov GV (2016) Waxes in asphaltenes of crude oils and wax deposits. Pet Sci 13(4): 737-745.

11. Garcia MC, Carbognani L (2001) Asphaltene-paraffin structural interactions. Effect on crude oil stability. Energ Fuel 15(5): 1021-1027.

12. Anisuzzaman SM, Yeow WF, Madsah M (2018) A review on various techniques and recent advances in polymeric additives to mitigate wax problems in crude oil. J Adv Res Fluid Mec Therm Sci 48 (1): 5364.

13. Bouts MN, Wiersma RJ, Muijs HM, Samuel AJ (1995) An evaluation of new aspaltene inhibitors; laboratory study and field testing. J Petrol Technol 47(9): 782787.

14. Garcia MC (2000) Crude oil wax crystallization. The effect of heavy n-paraffins and flocculated asphaltenes. Energ Fuel 14(5): 1043-1048.

15. Samieadel A, Hogsaa B, Fini EH (2018) Examining the implications of wax-based additives on the sustainability of construction practices: multiscale characterization of wax-doped aged asphalt binder. ACS Sustainable Chem Eng 7(3): 2943-2954.

16. Pahlavan F, Mousavi M, Hung A, Fini EH (2016) Investigating molecular interactions and surface morphology of wax-doped asphaltenes. Phys Chem Chem Phys 18(13): 8840-8854.

17. Carbognani L, Orea M (1999) Studies on large crude oil alkanes. I. High temperature liquid chromatography. Pet Sci Technol 17(1-2): 165-187.

18. Speight JG (2004) Petroleum asphaltenes Part 1: Asphaltenes, resins and the structure of petroleum. Oil \& Gas Sci Technol-Rev. IFP 59(5): 467-477.

19. Bono A, Anisuzzaman SM, Ding OW (2014) Effect of process conditions on the gel viscosity and gel strength of semi-refined carrageenan (SRC) produced from seaweed (Kappaphycus alvarezii). J King Saud Univ Eng Sci 26(1): 3-9.

20. Torgut G, Tanyol M, Biryan F, Pihtili G, Demirelli K (2017) Application of response surface methodology for optimization of Remazol Brilliant Blue R removal onto a novel polymeric adsorbent. J Taiwan Inst Chem E 80: 406-414. 


\section{Petroleum \& Petrochemical Engineering Journal}

21. Anisuzzaman SM, Abang S, Bono A, Krishnaiah D, Karali R, et al. (2017) Wax inhibitor based on ethylene vinyl acetate with methyl methacrylate and diethanolamine for crude oil pipeline. IOP Conf SerMat Sci 206(1): 1-8.

22. Anisuzzaman SM, Abang S, Bono A, Krishnaiah, Ismail NM, et al. (2017) An evaluation of solubility of wax and asphaltene in crude oil for improved flow properties using a copolymer solubilized in organic solvent with an aromatic hydrocarbon. Int J Chem Molecul Eng 11(10): 688-695.

23. Vieira LC, Buchuid MB, Lucas E F (2012) Effect of pressure on the performance of poly(ethylene-vinyl acetate) as wax deposition inhibitors by calorimetric method. J Appl Polym Sci 126(1): 143-149.

24. Ashbaugh HS, Radulescu A, Prud'homme RK, Schwahn D, Richter D, Fetters L J (2002) Interaction of paraffin wax gels with random crystalline/amorphous hydrocarbon copolymers. Macromolecules 35(18): 7044-7053.

25. Lashkarbolooki M, Esmaeilzadeh F, Mowla D (2011) Mitigation of Wax Deposition by Wax-Crystal Modifier for Kermanshah Crude Oil. J Disper Sci Technol 32(7): 975-985.
26. Soni HP, Kiranbala, Agrawal KS, Nagar A, Bharambe DP (2010) Designing maleic anhydride- $\alpha$-olifin copolymeric combs as wax crystal growth nucleators. Fuel Process Technol 91(9): 997-1004.

27. Soni HP, Kiranbala, Bharambe DP (2008) Performance based designing of wax crystal growth inhibitors. Energ Fuel 22(6): 3930-3938.

28. Ridzuan N, Adam F, Yaacob Z (2016) Evaluation of the inhibitor selection on wax deposition for Malaysian crude oil. Pet Sci Technol 34(4): 366-371.

29. Machado ALC, Lucas EF (2002) Influence of ethyleneco-vinyl acetate copolymers on the flow properties of wax synthetic systems. J Appl Polym Sci 85(6): 13371348.

30. Samuelson ML (1992) Alternatives to aromatics for solvency of organic deposits. Society of Petroleum Engineers, SPE Formation Damage Control Symposium, Lafayette, Louisiana, pp: 447.

31. Trbovich MG, King GE (1991) Asphaltene Deposit Removal: Long-Lasting Treatment With a Co-Solvent. Society of Petroleum Engineers, SPE International Symposium on Oilfield Chemistry, Anaheim, California, pp: 393. 